\title{
Propentofylline reduces glial scar development following gliotoxic damage in the rat brainstem
}

\author{
Propentofilina reduz o desenvolvimento da cicatriz glial após dano gliotóxico no tronco \\ encefálico de ratos
}

\author{
Eduardo Fernandes Bondan ${ }^{1,2}$, Maria de Fátima Monteiro Martins ${ }^{1,2}$, Pietro Domingues Dossa1, \\ Ligia Bocamino Viebig', Carolina Vieira Cardoso', João Lopes Martins Júnior'1, Maria Martha Bernardi1
}

\begin{abstract}
Propentofylline is a xanthine derivative that depresses activation of glial cells, whose responses contribute to neural tissue damage during inflammation. Ethidium bromide injection into the central nervous system induces local oligodendroglial and astrocytic loss, resulting in primary demyelination, neuroinflammation and blood-brain barrier disruption. Surviving astrocytes present a vigorous reaction around the injury site with increased immunoreactivity to glial fibrillary acidic protein (GFAP). Objective: This study aimed to evaluate the effect of propentofylline administration on astrocytic response following gliotoxic injury. Method: Wistar rats were injected with ethidium bromide into the cisterna pontis and treated or not with propentofylline $(12.5 \mathrm{mg} / \mathrm{kg} / \mathrm{day}$, intraperitoneal) during the experimental period. Brainstem sections were collected from 15 to 31 days after gliotoxic injection and processed for GFAP immunohistochemistry. Results and Conclusion: Results demonstrate that propentofylline decreased astrocytic activation until the $21^{\text {st }}$ day, suggesting that this drug may have a role in reducing glial scar development following injury.
\end{abstract}

Key words: astrocytes; ethidium; gliosis; gliotoxin; xanthine.

\begin{abstract}
RESUMO
A propentofilina é uma xantina que deprime a ativação das células gliais, cujas respostas contribuem para o dano neural durante inflamação. A injeção de brometo de etídio no sistema nervoso central induz a perda oligodendroglial e astrocitária, resultando em desmielinização, neuroinflamação e ruptura da barreira hematoencefálica. Os astrócitos sobreviventes apresentam vigorosa reação ao redor da lesão com aumento da imunorreatividade à proteína glial fibrilar ácida (GFAP). Objetivo: Este estudo objetivou avaliar o efeito da propentofilina sobre a resposta astrocitária após injúria gliotóxica. Método: Ratos Wistar foram injetados com brometo de etídio na cisterna basal e tratados ou não com propentofilina $(12.5 \mathrm{mg} / \mathrm{kg} /$ dia, intraperitoneal). Amostras do tronco encefálico foram coletadas dos 15 aos 31 dias pós-injeção do gliotóxico e processadas para estudo ultraestrutural e imuno-histoquímico para GFAP. Resultados e Conclusão: Os resultados demonstram que a propentofilina reduziu a ativação astrocitária até o $21^{\circ}$ dia, sugerindo que essa droga pode atuar na redução da cicatriz glial após injúria.
\end{abstract}

Palavras-chave: astrócitos; etídio; gliose; gliotoxina; xantina.

It is widely described that ethidium bromide (EB) injection in the white matter of the central nervous system (CNS) acts like a gliotoxin causing local oligodendroglial and astrocytic death, with consequent demyelination (although the naked axons remained preserved), blood-brain barrier disruption and Schwann cell invasion due to the glia limitans breakdown $n^{1,2,3}$. Surviving astrocytes presented a vigorous reaction around the injury site with increased immunoreactivity to the specific cell marker glial fibrillary acidic protein (GFAP) and reexpression of vimentin (VIM) ${ }^{2}$.
Propentofylline[PPF,3-methyl-1-(5'-oxohexyl)-7-propylxanthine] is a xanthine derivative with pharmacological effects distinct from those of the classical methylxanthines theophylline and caffeine $e^{4}$. In vitro and in vivo studies have demonstrated extensive neuroprotective, antiproliferative and anti-inflammatory effects of PPF in several experimental models in animals ${ }^{4}$. It was sucessfully used in degenerative vascular dementia and as a potential adjuvant treatment to Alzheimer's disease, schizophrenia and multiple sclerosis ${ }^{4}$. Propentofylline decreases activation of microglial cells and astrocytes, whose

${ }^{1}$ Universidade Paulista, Departamento de Patologia Ambiental e Experimental, São Paulo SP, Brasil;

${ }^{2}$ Universidade Cruzeiro do Sul, Departamento de Medicina Veterinária, São Paulo SP, Brasil.

Correspondence: Eduardo Fernandes Bondan; Rua Caconde, 125/51; 01425-011 São Paulo SP, Brasil; E-mail: bondan@uol.com.br

Conflict of interest: There is no conflict of interest to declare.

Received 29 February 2016; Received in final form 24 May 2016; Accepted 08 June 2016. 
responses are associated with neuronal damage during inflammation and hypoxia, and PPF consequently decreases glial production and release of damaging proinflammatory factors ${ }^{5,6}$.

In the EB-demyelinating model, PPF administration has been shown to significantly increase both oligodendroglial and Schwann cell remyelination following gliotoxic damage ${ }^{7}$ and even reverse the impairment in remyelination found in diabetic rats $^{8}$. Despite the beneficial effects of PPF observed on oligodendrocyte remyelinating activity in these investigations, astrocyte behavior has not been properly evaluated. Thus, the aim of this study was to evaluate whether PPF had the capacity to affect astrocyte responses during the process of demyelination and remyelination following gliotoxic injury induced by EB.

\section{METHOD}

The animal procedures were performed in accordance with the guidelines of the Committee on Care and Use of Laboratory Animal Resources and Brazilian Institutional Ethics Committee, Universidade Paulista (protocol number 182/13, CEUA/ICS/UNIP). Seventy-two adult (4-5-month-old) male Wistar rats were submitted to a local injection of 10 microlitres of $0.1 \%$ EB into the cisterna pontis, an enlarged subarachnoid space below the ventral surface of the pons. All rats were anaesthetized with ketamine and xylazine $(5: 1 ; 0.1 \mathrm{ml} / 100 \mathrm{~g})$ and $2.5 \%$ thiopental $(40 \mathrm{mg} / \mathrm{ml})$ by intraperitoneal route and a burr-hole was made on the right side of the skull, $8 \mathrm{~mm}$ behind the fronto-parietal suture. Injections were performed freehand using a Hamilton syringe, fitted with a $35^{\circ}$ angled polished 26 gauge needle into the cisterna pontis. Rats were then distributed into two groups - untreated rats (group I, $\mathrm{n}=36$ ) and rats treated with $12.5 \mathrm{mg} / \mathrm{kg} /$ day of PPF (Agener União Química, São Paulo, SP, $20 \mathrm{mg} / \mathrm{ml}$ solution) by intraperitoneal route during the experimental period (group II, $\mathrm{n}=36$ ). The animals were kept under controlled light conditions (12 h light-dark cycle) and water and food were given ad libitum during the experimental period.

For ultrastructural investigation, four rats from each group were anaesthetized and were submitted to intracardiac perfusion with $4 \%$ glutaraldehyde in $0.1 \mathrm{M}$ Sorensen phosphate buffer ( $\mathrm{pH} 7.4$ ) at each of the following periods - 15, 21 and 31 days post-injection (p.i.). Thin slices of the brainstem (pons and mesencephalon) were collected and post-fixed in $0.1 \%$ osmium tetroxide, dehydrated with graded acetones and embedded in Araldite 502 resin, following transitional stages in acetone. Thick sections were stained with $0.25 \%$ alkaline toluidine blue. Selected areas were trimmed and thin sections were stained with $2 \%$ uranyl and lead acetate and viewed in a JEM -1200 EX2 JEOL transmission electron microscope.

For immunohistochemical study of the expression of the astrocytic marker GFAP, eight rats were anaesthetized and submitted to intracardiac perfusion with buffered $10 \%$ formaldehyde solution at each of the same periods. Their brains were then removed and kept for three days in the same fixative. Coronal sections from the brainstem were mounted on silanized slides and submitted to GFAP immunostaining using the avidin-biotin peroxidase complex (ABC) method. Briefly, the sections were deparaffinized in xylene and rehydrated in a crescent graded series of ethanol solutions. Antigen retrieval was done by transferring the slides to $10 \mathrm{mM}$ sodium citrate buffer ( $\mathrm{pH}$ 6.0) at $95^{\circ} \mathrm{C}$ for 20 minutes. Endogenous peroxidase was blocked by $3 \%$ hydrogen peroxide for 10 minutes at room temperature. Two washes with Tris/HClbufferpH6.0(Wash buffer 10x, S3006, Dako, Glostrup, Danmark) were done between incubations. Polyclonal rabbit anti-GFAP immunoglobulin (Z0334, Dako), at a dilution of 1:1000, was used as primary antibody, for 16 hours, followed by the application of biotinylated secondary antibody (Dako Universal LSAB ${ }^{\mathrm{TM}} 2$ System - HRP, K0690), according to the manufacturer's instructions. Immunoreactivity was visualized by incubating the sections in a solution containing $0.1 \%$ diaminobenzidine (DAB, K3467, Dako). Sections were then counterstained by Harris' modified hematoxylin solution, dehydrated and mounted in Entellan (Merck, Germany).

Astrocytic evaluation was done in the brainstem of animals from both groups using a computerized image analysis system (Image-Pro-Plus 4.5, Media Cybernetics, Silver Spring, USA), measuring, by colorimetry, the area stained brown in a total area of 302,952.5 $\mu^{2}$. Negative controls for immunostaining (sections lacking primary antibody application) were done. Data were analyzed by $t$ test and statistical significance was set at $\mathrm{p}<0.05$.

\section{RESULTS}

The general aspect of the EB-induced lesions found in this investigation in both groups at 15, 21 and 31 days was similar to that previously described in other studies using this gliotoxin in the rat brainstem ${ }^{1,2}$ (Figure 1). Briefly, they presented extensive demyelinated areas in the ventral surface of the mesencephalon and pons and contained, in the central region, phagocytic cells, myelin debris and naked axons. At the periphery, oligodendrocytes and Schwann cells were observed, the latter occurring in areas of enlarged extracellular spaces devoid of astrocytic extensions. Astrocyte processes were invariably seen near the incipient, but preponderant, oligodendroglial remyelination at the periphery, and Schwann cells also appeared to contribute to myelin repair. Ultrastructural analysis apparently showed that astrocytic processes among oligodendrocyte remyelinated axons were slightly thinner in PPF-treated animals (Figure 2B) compared to those that had not received the xanthine (Figure 2A). Although oligodendroglia prevailed in the brainstem myelin repair from the $15^{\text {th }}$ to the $31^{\text {st }}$ day, sheaths formed by Schwann cells in astrocyte-free areas were thicker than those produced by oligodendrocytes during the same period. 
As described earlier in a former investigation ${ }^{7}$, PPF-treated rats presented an increased remyelination from the $15^{\text {th }}$ to the $31^{\text {st }}$ day following EB injection. Some lymphocytes and infiltrating pial cells were occasionally seen, the first contacting phagocytic cells and myelin debris.

By GFAP immunohistochemical staining, it was observed that the EB-induced lesions from group II (PPF-treated rats) apparently presented a decreased astrocytic reaction close to

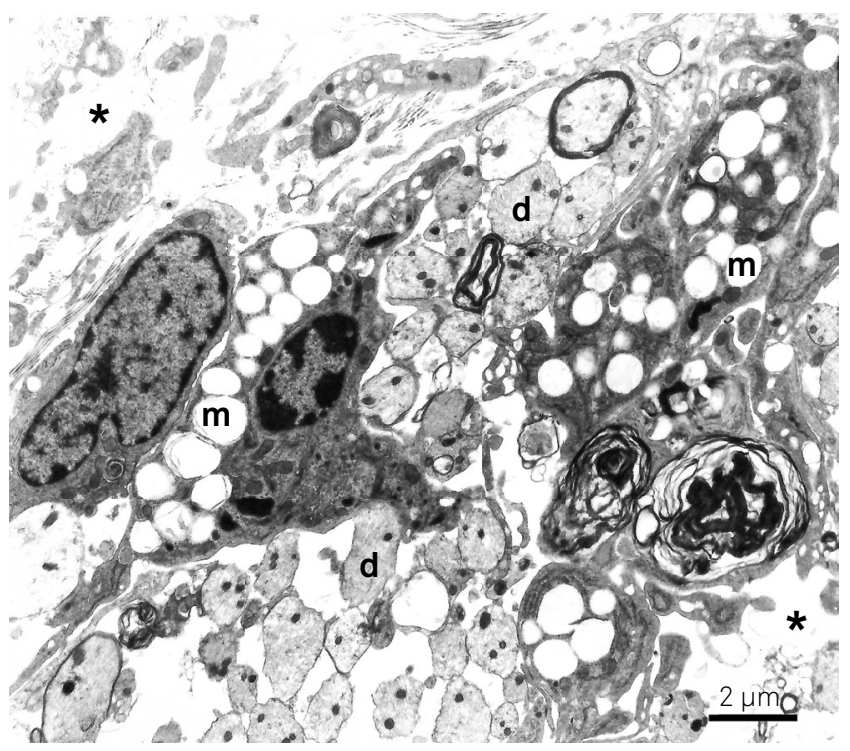

Figure 1. Electronmicrograph from a central area at 15 days following ethidium bromide (EB) injection in rats not treated with propentofylline (PPF). Demyelinated axons (d) and macrophages $(m)$ in different stages of myelin degradation are seen in a distended extracellular space (asterisk). Bar $=2 \mu \mathrm{m}$. the edges of the injury site, with the observation of fewer and thinner GFAP-stained processes at the periphery at both 15 days (Figure 3A,B) and 21 days (Figure 3C,D). No astrocytes were observed in the central areas of the lesions from both groups even at 31 days after EB injection.

The Table presents the mean areas with GFAP staining in $\mu \mathrm{m}^{2}$ from both groups at all analyzed periods $(15,21$ and 31 days). These results showed that, at 15 days, the mean brownstained area was significantly smaller in rats treated with PPF (group II - 41,653 \pm 7,306.61 $\mu^{2}$ ) compared to untreated rats (group I - 55,391.38 $\pm 5,819.91 \mu \mathrm{m}^{2}$ ). A similar finding was seen at 21 days $\left(44,829.38 \pm 6,164.66 \mu \mathrm{m}^{2}\right.$ in group II versus $55,381.75 \pm 5,785.65 \mu^{2}$ in group I), but no statistical difference was seen at 31 days (mean areas of 50,227.38 \pm 7,612.02 $\mu^{2}$ and $50,020.37 \pm 6,308.2 \mu \mathrm{m}^{2}$, respectively, in groups I and II).

\section{DISCUSSION}

Astrocytes respond to all forms of CNS insults through a process referred to as reactive astrogliosis, which is a finely gradated continuum of progressive changes in gene expression and cell morphology ${ }^{9,10}$. Intermediate filaments of astrocytes are composed mainly of GFAP and this protein has become the best-known astrocytic marker ${ }^{11}$. In mild reactive astrogliosis there is variable upregulation of expression of GFAP and other genes as well as hypertrophy of the cell body and processes, but this occurs within the domains of individual astrocytes without significant overlap of processes of neighboring astrocytes or loss of individual domains ${ }^{12}$. In this discrete reaction there is little or no astrocyte proliferation,
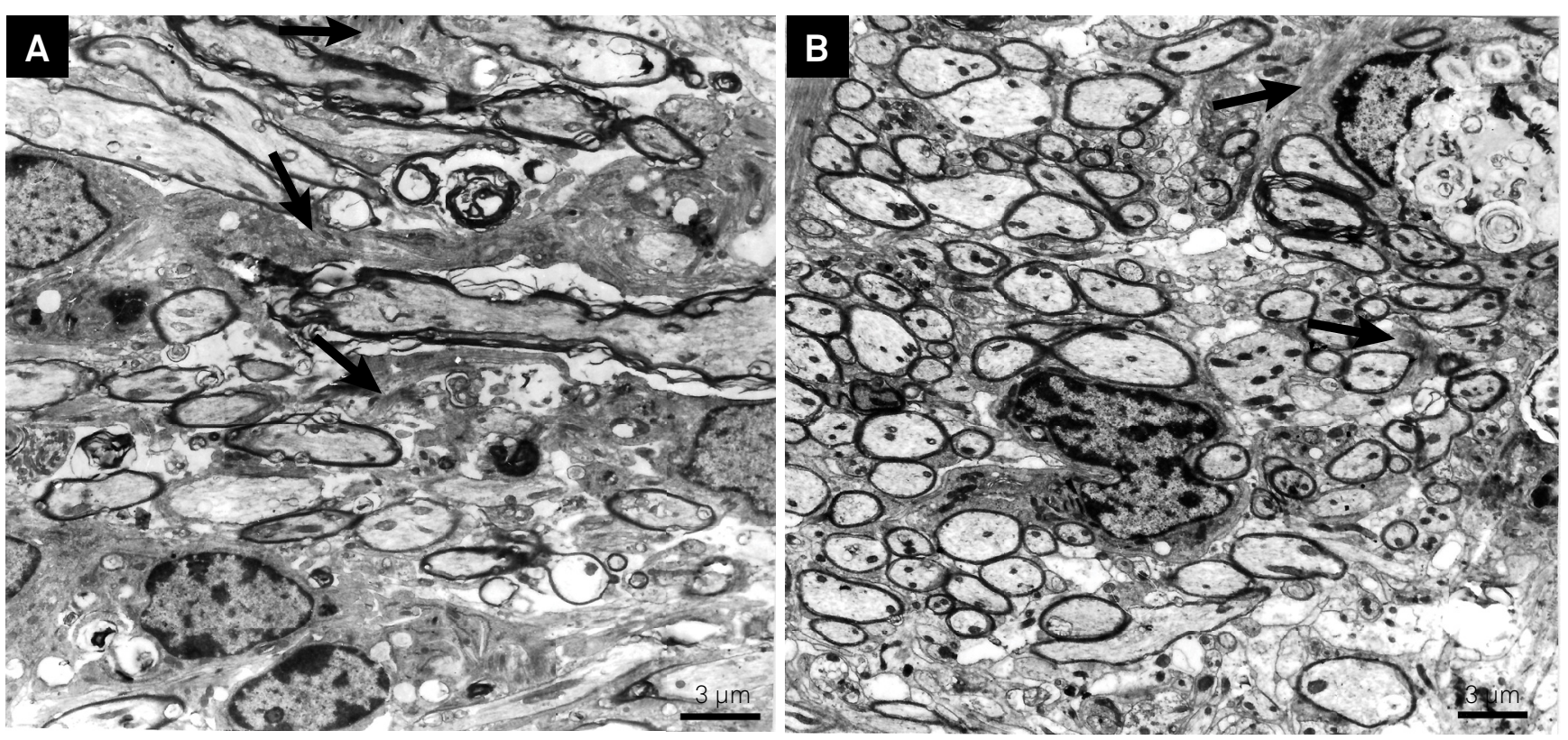

Figure 2. Electronmicrographs from peripheral areas of the ethidium bromide (EB)-induced lesions in untreated (A) and propentofylline (PPF)-treated (B) rats in the ventral surface of the pons at 21 days. Arrows indicate astrocytic processes. Note the thicker astrocyte processes among oligodendrocyte remyelinated axons in A (no treatment) and the greater amount of remyelinated axons in B (PPF treatment). A) Bar $=3 \mu \mathrm{m}$; B) Bar $=3 \mu \mathrm{m}$. 


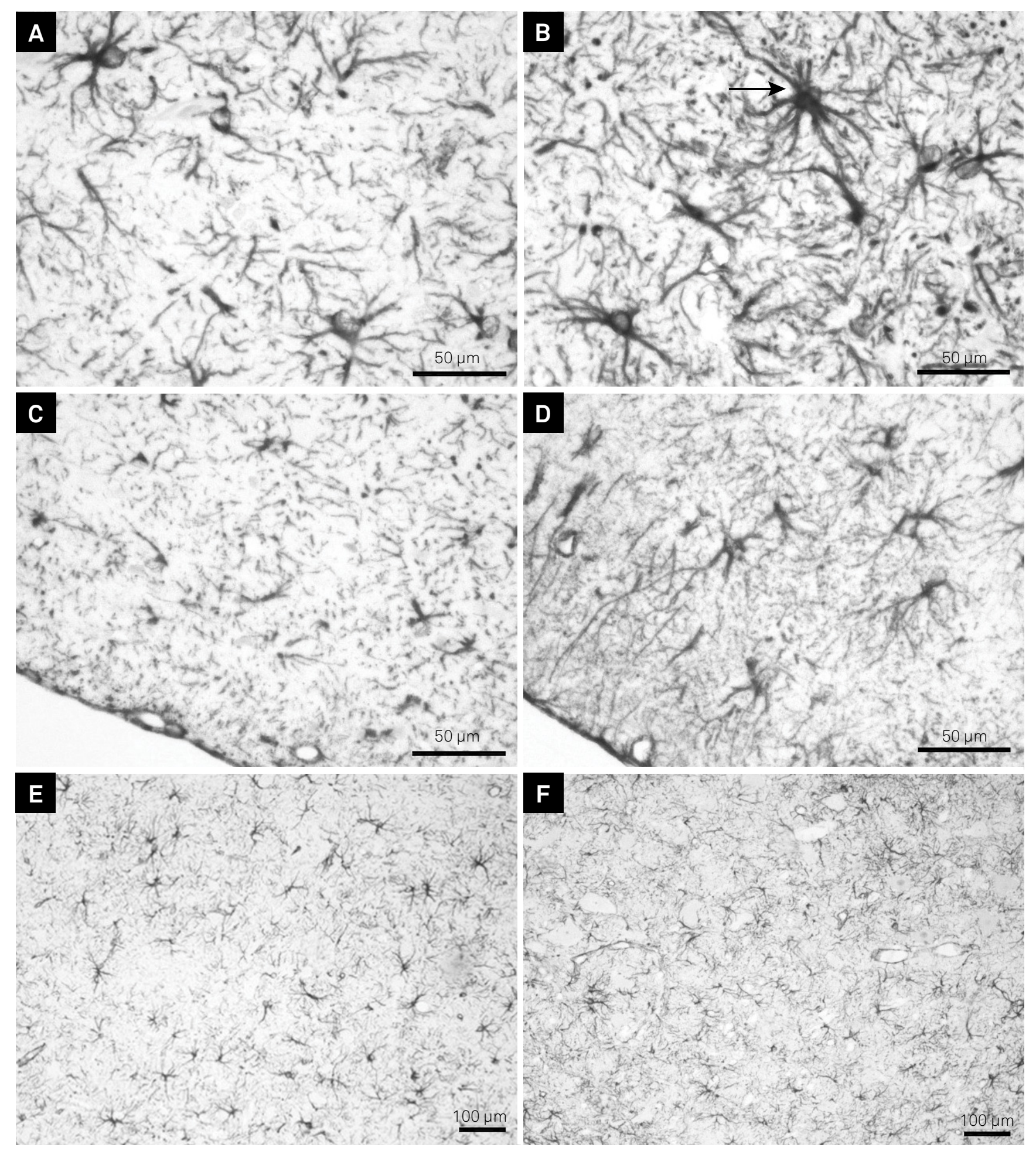

Figure 3. Peripheral glial fibrillary acidic protein (GFAP) expression by immunohistochemistry in the ventral surface of the

pons at 15 days (A, B), 21 days (C, D) and 31 days ( $E, F)$ in ethidium bromide (EB)-induced lesions from untreated (B, D, F) and

propentofylline (PFF)-treated (A, C, E) rats. Observe a strongly stained GFAP-positive astrocyte (arrow) in B. (A, B, C, D) Bar = 50 $\mu$ m;

$\mathrm{E}, \mathrm{F}) \mathrm{Bar}=100 \mu \mathrm{m}$

but the increased expression of GFAP can lead to the staining of more cells, giving the false impression of proliferation ${ }^{12,13}$. On the other hand, severe astrogliosis leads to a more pronounced upregulation of GFAP, among other genes, with blurring and disruption of individual astrocyte domains, as usually found in areas surrounding severe focal lesions ${ }^{12}$.
Astrocyte precursors and immature astrocytes present principally nestin and vimentin (VIM) and, during development, as astrocytes mature, nestin expression disappears, GFAP becomes increasingly expressed and VIM decreases to undetectable levels ${ }^{11}$. In both mild or severe astrogliosis, astrocytes also reexpress VIM and nestin ${ }^{11}$. In the EB demyelinating model, 
Table. Areas with glial fibrillary acidic protein (GFAP) staining in $\mu \mathrm{m}^{2}$ in a total area of $302,952.5 \mu \mathrm{m}^{2}$ in rats injected with ethidium bromide (EB), treated (group II) or not (group I) with propentofylline (PPF).

\begin{tabular}{|c|c|c|c|c|c|c|}
\hline \multirow{2}{*}{ Animal } & \multicolumn{3}{|c|}{ Group I - EB injection } & \multicolumn{3}{|c|}{ Group II - EB injection + PPF } \\
\hline & 15 days & 21 days & 31 days & 15 days & 21 days & 31 days \\
\hline 1 & 50,231 & 45,924 & 39,523 & 47,292 & 45,435 & 46,417 \\
\hline 2 & 60,812 & 50,125 & 58,126 & 39,548 & 36,021 & 58,352 \\
\hline 3 & 48,154 & 54,531 & 45,132 & 51,63 & 43,19 & 55,325 \\
\hline 4 & 53,824 & 56,642 & 44,243 & 40,226 & 47,611 & 45,131 \\
\hline 5 & 57,122 & 56,134 & 55,232 & 34,135 & 47,163 & 47,361 \\
\hline 6 & 61,326 & 57,288 & 56,785 & 36,177 & 56,236 & 44,372 \\
\hline 7 & 62,451 & 58,125 & 44,457 & 50,723 & 44,634 & 44,527 \\
\hline 8 & 49,211 & 64,915 & 58,321 & 33,453 & 38,345 & 58,678 \\
\hline Mean & $55,391 \cdot 38^{A}$ & $55,381.75^{A}$ & $50,227.38^{c}$ & $41,653^{\mathrm{B}}$ & $44,829 \cdot 38^{B}$ & $50,020.37^{c}$ \\
\hline SD & $\pm 5,819.91$ & $\pm 5,785.65$ & $\pm 7,612.02$ & $\pm 7,306.61$ & $\pm 6,164.66$ & $\pm 6,308.2$ \\
\hline
\end{tabular}

SD: standard deviation; distinct letters indicate significant differences between groups I and II at each period ( $p<0.05)$.

reexpression of VIM and strong astrocytic immunoreactivity to GFAP were described by Bondan et al. ${ }^{2}$ in the rat brainstem from the $3^{\text {rd }}$ to the $31^{\text {st }}$ day following gliotoxic injection. This increased GFAP expression around the EB-induced lesions was also confirmed in the present study, in a pattern suggestive of mild astrogliosis.

Many different types of signaling molecules are able to trigger and/or regulate astrogliosis and can be released by all cell types of the CNS tissue, including neurons, microglia, oligodendrocyte lineage cells, pericytes, endothelia and other astrocytes, as well as by invasive inflammatory/immune cells ${ }^{12,13}$.

While it was initially thought that astrocyte proliferation was a major component of glial scar, it has been repeatedly demonstrated that there are actually few astrocytes undergoing cell division during glial scar formation ${ }^{9}$. This observation is confirmed by the fact that no astrocytes in mitotic activity were seen in this study and also in previous investigations focusing on astrocytic response following gliotoxic lesions ${ }^{2}$.

Concerning the mechanisms of PPF action, it has been shown that (i) inhibition of cyclic AMP and GMP-phosphodiesterases (PDE), (ii) inhibition of membrane adenosine transporters and (iii) reinforcement of adenosine $\mathrm{A}_{2}$ receptor-mediated effects in a synergistic manner are potent pathways responsible for the protective adenosine-mediated actions of this xanthine ${ }^{4,14}$. There is also evidence that PPF is a weak adenosine autoreceptor $\mathrm{A}_{1}$ antagonist, which can additionally inhibit its reuptake and the activity of the $5^{\prime}$-nucleotidase ${ }^{14}$.

Thus, PPF leads to increased intracellular cAMP levels and greater extracellular concentrations of adenosine, stimulating adenosinergic neurotransmission and adenosine $2\left(\mathrm{~A}_{2}\right)$ receptor-mediated cAMP synthesis ${ }^{5,15}$.

Intracellular levels of the second messenger cAMP can be elevated by activation of the adenylate cyclase or by inhibition of cAMP-degrading phosphodiesterases (PDE). Eleven PDE families have been identified with different specificity towards cAMP and cGMP ${ }^{16}$.

Regulation of cytokine production includes the adenylate cyclase - cAMP - protein kinase pathway ${ }^{17}$. Yoshiwawa et al. ${ }^{18}$ reported that PPF, a type III-IV specific PDE inhibitor, although decreasing in a dose-dependent manner the production of the inflammatory cytokines TNF- $\alpha$, IL- 1 and IL- 6 by mouse microglia stimulated by LPS in vitro, increased up to two or three times the production of the inhibitory cytokine IL-10. In turn, IL-10 acts by suppressing cytokine release by microglia and macrophages and attenuating astroglial reactivity in vivo ${ }^{19}$.

The GFAP is regulated in part by the secretion of factors into the extracellular space. The common pathway for GFAP expression in astrocytes is triggered by the binding of cytokines from the IL-6 family to their receptors. These receptors subsequently activate the JAK/STAT intracellular pathway, leading to the expression of GFAP in astrocytes. Most of the other pathways known to participate in GFAP expression are connected at some point to this pathway. For example, some members of the TGF- $\beta$ superfamily of cytokines have little or no effect on GFAP synthesis by themselves, but they strongly potentiate GFAP induced by the IL- 6 family of cytokines ${ }^{20}$. The PDE inhibitor pentoxifylline is also known to decrease the synthesis of TNF- $\alpha$, IL- $1 \beta$ and IL- 6 through the inhibition of nuclear factor- $\kappa \mathrm{B}$ and stimulation of IL-10 expression in the $\mathrm{CNS}^{21,22}$. In the EB demyelinating model, PPF has already been shown to decrease the production of TNF- $\alpha$ and IL- $1 \beta$ in the rat brainstem ${ }^{23}$.

In the CNS, PPF acts as a glial modulator, with direct actions on microglia, decreasing microglial proliferation and expression of inflammatory cytokines, such as TNF- $\alpha$ and IL-1 $\beta$, in vitro and in vivo $0^{6,14,18,24}$.

In the present study, PPF was shown to decrease the astrocytic reaction to the gliotoxic injury as seen through the expression of GFAP and by ultrastructural observation. Morphometric analysis confirmed, at 15 and 21 days the initial impression suggested by the observation of semithin and ultrathin sections, that PPF treatment decreased the astrocytic reaction to the gliotoxic injection as peripheral GFAP stained areas were significantly greater in EB injected rats that were not treated with PPF compared to rats treated with the xanthine.

Decreased activation of astrocytes and microglia in rats treated with PPF, as shown by reduced GFAP and OX-42 expression, 
respectively, was also observed in vivo by Young et al..$^{25}$ after spinal cord injury. The PPF also inhibited injury-induced GFAP expression along with enhancement of glutamate transporters GLT-1 and GLAST in the dorsal horn upper laminae in mice submitted to L5-spinal nerve transection ${ }^{26}$.

Activated astrocytes may lose their homeostatic functions upon exposure to stressors, decreasing glutamate uptake and increasing the expression of deleterious proinflammatory molecules such as cytokines, nitric oxide, prostaglandins, among others, as an injury response ${ }^{13}$. Thus, reactive astrocytes display decreased glutamate transporters and as a result synaptic glutamate clearance is impaired. In vitro PPF was capable of differentiating astrocytes back to a homeostatic, mature phenotype, competent for glutamate clearance ${ }^{26}$.

Both oligodendrocyte and astrocyte loss are hallmarks within the epicenter of an EB lesion while axons remain unaffected. The mechanism of selective glial death has been suggested to occur through EB's action as a minor-groove DNA intercalator ${ }^{3}$. However, other evidences suggest that while EB does intercalate both chromosomal and mitochondrial DNA, it only affects transcription of mtDNA ${ }^{27}$. So, it is likely that EB injection into the white matter compromises mtDNA in all cells in the lesion site although neurons and endothelial cells appear to be less sensitive than glia in rat models ${ }^{3}$.

After trauma, blood-brain barrier dysfunction is immediately observed as well as activation of inflammatory cells including microglia, astrocytes and invading monocytes/macrophages ${ }^{1,2,3}$. Activation and recruitment of inflammatory cells into the injured CNS generate proinflammatory cytokines, free radicals and other damaging molecules. The two most important cytokines found in the CNS after trauma are TNF- $\alpha$ and IL- $1 \beta$, which are highly cytotoxic and regulated by cAMP signaling ${ }^{16}$. The benefits of PDE4 inhibition in reducing inflammation have been well studied in rodent models of ischemia ${ }^{14}$ and traumatic inju$\mathrm{ry}^{16}$. PDE4 inhibitors have been found to improve neuronal survival, reduce infarct size, and attenuate inflammation and blood-brain barrier breakdown ${ }^{28}$. In experimental autoimmune encephalomyelitis, rolipram, a PDE4 inhibitor, prevents the progression of neurodegeneration and demyelination by increasing cAMP levels ${ }^{29,30}$.

It is possible that macrophage and lymphocyte products during the inflammatory response triggered by the EB injection may provide a greater harmful influence to the nervous tissue than the early gliotoxin injection itself. Therefore the anti-inflammatory effects performed by PPF may possibly be beneficial to remyelination.

A $\mathrm{Ca}^{++}$-dependent and excessive activation of glial cells is usually found in neuroinflammation and, in this context, increased levels of adenosine induced by PPF administration may perform a regulatory role on these $\mathrm{Ca}^{++}$- and cAMP-dependent molecular signaling pathways that determine many cell-related functions, such as cellular proliferation rate, differentiation state, cytokine production, among others ${ }^{5}$.

A strengthening of the cAMP signaling, which can be achieved by adenosine agonists and by PPF, stimulates the production of neurotrophic factors in astrocytes, apparently preventing a deleterious and secondary astrocytic activation caused by previous microglial upregulation ${ }^{15}$.

Although not entirely understood, it has been accepted that drugs that elevate extracellular adenosine and/or block the degradation of cyclic nucleotides, like PPF, may be used to counteract glia-related damage in CNS pathological processes ${ }^{15}$.

Thus, ultrastructural observation along with morphometric analysis in the present study unequivocally demonstrated that PPF decreased astrocytic activation until the $21^{\text {st }}$ day after gliotoxic lesion, probably by simultaneously suppressing the release of proinflammatory molecules, such as the above mentioned TNF- $\alpha$ and IL-1 $\beta$, as well as IL-6, which may trigger and promote astrogliosis following CNS injury, and by increasing secretion of the anti-inflammatory cytokine IL-10.

In conclusion, our results clearly indicate that PPF may have a role in preventing or reducing glial scar development following injury.

\section{References}

1. Bondan EF, Lallo MA, Sinhorini IL, Pereira LAVD, Graça DL. The effect of cyclophosphamide on brainstem remyelination following local ethidium bromide injection in Wistar rats. J Submicrosc Cytol Pathol. 2000;32(4):603-12.

2. Bondan EF, Lallo MA, Dagli MLZ, Sanchez M, Graça DL. [Investigation into the astrocytic immunoreactivity to GFAP and vimentin in the brainstem of Wistar rats submitted to the ethidium bromide gliotoxic model]. Arq Neuropsiquiatr. 2003;61(3A):642-9. Portuguese. doi:10.1590/S0004-282X2003000400022

3. Kuypers NJ, James KT, Enzmann GU, Magnuson DSK, Whittemore SR. Functional consequences of ethidium bromide demyelination of the mouse ventral spinal cord. Exp Neurol. 2013;247:615-22. doi:10.1016/j.expneurol.2013.02.014

4. Sweitzer S, De Leo J. Propentofylline: glial modulation, neuroprotection, and alleviation of chronic pain. Handb Exp Pharmacol. 2011;200:235-50. doi:10.1007/978-3-642-13443-2_8
5. Schubert P, Ogata T, Rudolphi K, Marchini C, McRae A, Ferroni, S. Support of homeostatic glial cell signaling: a novel therapeutic approach by propentofylline. Ann NY Acad. Sci. 1997;826:337-47. doi:10.1111/j.1749-6632.1997.tb48484.x

6. Si, Q, Nakamura Y, Ogata T, Kataoka K, Schubert P. Differential regulation of microglial activation by propentofylline via cAMP signaling. Brain Res. 1998;812(1-2):97104. doi:10.1016/S0006-8993(98)00954-8

7. Bondan EF, Martins MFM, Baliellas DEM, Gimenez CFM, Poppe SC, Bernard MM. Effects of propentofylline on CNS remyelination in the rat brainstem. Microsc Res Tech. 2014;77(1):23-30. doi:10.1002/jemt.22308

8. Bondan EF, Martins MFM, Bernardi MM. Propentofylline reverses delayed remyelination in streptozotocin-induced diabetic rats. Arch Endocrinol Metab. 2015;59(1):47-53. doi:10.1590/2359-3997000000009 
9. Fitch MT, Silver J. Astrocytes are dynamic participants in central nervous system development and injury responses. In: Jessen KR, Richardson WD. Glial cell development. Oxford: Oxford University Press; 2001. p. 263-77.

10. Cregg JC, DePaul MA, Filous AR, Lang GBT, Tran A, Silver J. Functional regeneration beyond glial scar. Exp Neurol. 2014;253:197-207. doi:10.1016/j.expneurol.2013.12.024

11. Pekny M, Pekna A. Astrocyte intermediate filaments in CNS pathologies and regeneration. J Pathol. 2004;204(4):428-37. doi:10.1002/path.1645

12. Sofroniew MV, Vinters HV. Astrocytes: biology and pathology. Acta Neuropathol. 2010;119(1):7-35. doi:10.1007/s00401-009-0619-8

13. Sofroniew MV. Molecular dissection of reactive astrogliosis and glial scar formation. Trends Neurosci. 2009;32(12):638-47. doi:10.1016/j.tins.2009.08.002

14. Plaschke K, Grant M, Weigand MA, Züchner J, Martin E, Bardenheuer HJ. Neuromodulatory effect of propentofylline on rat brain under acute and long-term hypoperfusion. Br J Pharmacol. 2001;133(1):107-16. doi:10.1038/sj.bjp.0704061

15. Schubert P, Morino T, Miyazaki H, Ogata T, Nakamura Y, Marchini $\mathrm{C}$ et al. Cascading glia reactions: a common pathomechanism and its differentiated control by cyclic nucleotide signaling. Ann N Y Acad Sci. 2000;903:24-33. doi:10.1111/j.1749-6632.2000.tb06346.x

16. Titus DJ, Oliva AA, Wilson NM, Atkins CM. Phosphodiesterase inhibitors as therapeutics for traumatic brain injury. Curr Pharm Des. 2014;21(3):332-42. doi:10.2174/1381612820666140826113731

17. Kammer GA. The adenylate cyclase-cAMP-protein kinase A pathway and regulation of the immune response. Immunol Today. 1988;9(7-8):222-9. doi:10.1016/0167-5699(88)91220-0

18. Yoshikawa M, Suzumura A, Tamaru T, Takayanagi T, Sawada M. Effects of phosphodiesterase inhibitors on cytokine production by microglia. Mult Scler. 1999;5(2):126-33. doi:10.1177/135245859900500210

19. Balasingam $\mathrm{V}$, Yong $\mathrm{VW}$. Attenuation of astroglial reactivity by interleukin-10. J Neurosci. 1996;16(9):2945-55.

20. Herrera F, Chen Q, Schubert D. Synergistic effect of retinoic acid and cytokines in the regulation of glial fibrillary acidic protein expression. J Biol Chem. 2010;285(50):38915-22. doi:10.1074/jbc.M110.170274
21. Neuner P, Klosner G, Schauer E, Pourmojib M, Macheiner W, Grünwald $C$ et al. Pentoxifylline in vivo down-regulates the release of IL-1 $\beta, I L-6, I L-8$ and tumour necrosis factor- $\alpha$ by human peripheral blood mononuclear cells. Immunol. 1994;83(2):262-7.

22. Lundblad R, Ekstrøm P, Giercksky KE. Pentoxifylline improves survival and reduces tumor necrosis factor, interleukin-6, and endothelin-1 in fulminant intra-abdominal sepsis in rats. Shock. 1995;3(3):210-5. doi:10.1097/00024382-199503000-00009

23. Bondan EF. Propentofylline decreases the production of TNF-alpha and IL-1 in the rat brainstem after a gliotoxic injury induced by ethidium bromide. J Neuroimmunol. 2014;275:139. doi:10.1016/j.jneuroim.2014.08.373

24. Jung S, Donhauser T, Toyka KV, Hartung HP. Propentofylline and iloprost suppress the production of TNF- $\alpha$ by macrophages but fail to ameliorate experimental autoimmune encephalomyelitis in Lewis rats. J Autoimmun. 1997;10(6):519-29. doi:10.1006/jaut.1997.0159

25. Gwak YS, Crown ED, Unabia GC, Hulsebosch CE. Propentofylline attenuates allodynia, glial activation and modulates GABAergic tone after spinal cord injury in the rat. Pain. 2008;138(2):410-22. doi:10.1016/j.pain.2008.01.021

26. Tawfik VL, Regan MR, Haenggeli C, LaCroix-Fralish ML, Nutile-McMenemy N, Perez N et al. Propentofylline-induced astrocyte modulation leads to alterations in glial glutamate promoter activation following spinal nerve transection. Neuroscience. 2014;152(4):1086-92. doi:10.1016/j.neuroscience.2008.01.065

27. Hayakawa T, Noda M, Yasuda K, Yorifuji H, Taniguchi S, Miwa l et al. Ethidium bromide-induced inhibition of mitochondrial gene transcription suppresses glucose-stimulated insulin in the mouse pancreatic beta-cell line betaHC9. J Biol Chem. 1998;273(32):20300-7. doi:10.1074/jbc.273.32.20300

28. Li, LX, Cheng YF, Lin HB, Wang C, Xu JP, Zhang HT. Prevention of cerebral ischemia-induced memory deficits by inhibition of phosphodiesterase-4 in rats. Metab Brain Dis. 2011;26(1):37-47. doi:10.1007/s11011-011-9235-0

29. Sommer N, Löschmann PA, Northoff GH, Weller M, Steinbrecher A, Steinbach JP et al. The antidepressant rolipram suppresses cytokine production and prevents autoimmune encephalomyelitis. Nat Med. 1995;1(3):244-8. doi:10.1038/nm0395-244

30. Paintlia AS, Paintlia MK, Singh I, Skoff RB, Singh AK. Combination therapy of lovastatin and rolipram provides neuroprotection and promotes neurorepair in inflammatory demyelination model of multiple sclerosis. Glia. 2009;57(2):182-93. doi:10.1002/glia.20745 